\title{
IT Capability Evaluation through the IT Capability Map
}

\author{
Mina Ranjbarfard * \\ Faculty of Social Sciences and Economics, Alzahra University, Iran \\ m.ranjbarfard@alzahra.ac.ir \\ Seyedeh Reyhaneh Mirsalari \\ Faculty of Social Sciences and Economics, Alzahra University, Iran \\ Reyhaneh.mirsalari3168@gmail.com
}

Received: 11/Aug/2020 Revised: 14/Nov/2020 Accepted: 23/Nov/2020

\begin{abstract}
Organizations are increasingly in search of ways to derive more business values from IT investments and the need for IT capabilities (ITC) is surging. ITC is critical significant to build enterprise agility and promote organizational performance. However, IT capability is always treated as the causal factor already existing and there are few studies on how IT capability is created and evaluated. Appropriate evaluation is necessary for an organization to measure, manage and improve enterprise ITC. This research aims to identify and map the dimensions of an organization's ITC. Using a mixed research method, this paper comprises two sections. The qualitative section adopts a systematic literature review (SLR) approach to identify the dimensions of ITC. The quantitative section employs factor analysis to validate identified ITC dimensions and their indicators in an attempt to develop a more precise model for ITC evaluation. The proposed ITC model includes IT management, IT human resources, IT infrastructure, and implementation of IT solutions dimensions as well as the 25 related indicators. Drawing on the results of this paper, organizations can engage in evaluation and improve/create essential ITCs based on the evaluation results.
\end{abstract}

Keywords: Information technology capability; Information technology capability evaluation indicators; Information technology dimensions; Information technology map.

\section{1- Introduction}

Information System (IS) and Information Technology (IT) play a vital role in supporting business activities and technology that are intended to realize the vision, mission and goals that contribute to the growth of an organization [1] [2]. Lack of analysis and sound governance over the optimization of IT advantages, or the use of IT resources [1] [3] [4] [5], as well as the management of the risks associated with IT are the underlying factors that inhibit organization from IT investment such as Information system deployment [6] [7] [8]. IT capability (ITC) can compensate for this shortcoming [1] [9] [10]. ITC describes an organization's ability to create business value and to acquire, deploy, combine, and reconfigure IT resources in order to support and upgrade business strategies and business processes [11] [18] [19] [20]. The actual performance benefits of IS integration in an organization can only be accomplished if its IT capability is well controlled and governed [2] [21] [22] [23] [24]. As a result, recognizing all types of organization's ITC and its realistic evaluation is critical for building and cultivating IT resources. In addition, clarification of the relationship between ITC and organizational performance calls for ITC measurement and evaluation [25] [26], which must be examined quantitatively and qualitatively. The bulk of previous research have considered ITC as a platform and infrastructure for organizational activities and work flows. Despite the above, scant attention has been paid to the evaluation of overall organization's IT capability in the literature with some studies just mapping the types of IT capability and its drivers [27] [28] [29] [30]. On the other hand, the modelling and mapping of organizational capability has offered an approach to the creation of enterprise architecture. It seeks to develop a model for the complete set of capabilities required by an organization to fulfil its mission. Some frameworks are related to ITC in the realm of enterprise architecture. One of such frameworks is COBIT, which highlights the central role of IT in building business value and helping managers in connection with IT governance and the IT management by considering the business requirements, capabilities and IT resources, as well as different stakeholders of organizational needs. COBIT framework maintains a balance between benefits, risks and resources of organizations [31]. As noted in previous research, ITC covers a wide range of capabilities [27] [28] [29] [30], which must be controlled and evaluated, but COBIT framework only focuses on integrating enterprise governance and IT governance, and therefore a complete assessment of IT capability cannot be made under COBIT

\footnotetext{
* Corresponding Author
} 
framework. IT capability must be enhanced based on an evaluation results using valid indicators.

It is worth noting, however, that IT capabilities are a competitive necessity, as their absence can pose a competitive disadvantage. Given the importance of ITC issue, the question raised in this research is "What are the dimensions of ITC and its indices?"

This research seeks to address this gap in the literature in two sections: a qualitative section that examines the foundation (ITC dimensions and its indicators) through a systematic literature review (SLR) and EA expert interviews, and a quantitative section that focuses on developing a model for evaluating ITC based on the SLR information, data analysis, and the standpoints of EA experts for the purpose of organizational ITC evaluation.

\section{2- Background}

Organizational capability suggests that an organization should be organized and managed to take the most out of its resources. Subsequently, ITC is defined as IT resources deployed concurrent with other resources and capabilities [27] [32]. According to the concept of IT capability (ITC) proposed by Ross et al. [1], "IT capability represents the ability of an organization to collect, integrate and deploy IT resources". Hence, may studies have investigated the role of IT capability as an organizational capability for enhancing and improving organizational performance [2] [3] [10] [11] [12] [13] [14] [15] [16]. In fact, for the first time, the concept of ITC has been developed from a resource-based approach, according to which superior organizational performance is attributed to an organization's resources and capabilities [11] [12]. IT capability is a rare, non-reproducible, and nonsubstitutable organizational ability that offers great benefits when deployed perfectly [25]. rapid and innovative response are crucial to foster organizational agility. According to this view, ITC manifests a fundamental ability to influence the rapidness of organization [19] [26]. ITC can create time lag before opponents forcefully devastate the competitive advantage of an organization [34] [26], serving as a strategic obstacle to other competitors. Some studies classify ITC into three dimensions: IT infrastructure capability, IT business spanning capability, and IT proactive stance [19] [21] [35] [36] [37]. The first dimension reinforces processing and management of data accurately, creation of network channels, access to updated information about customer preferences as well as the latest technology and new regulations [19] [36]. Infrastructure integration can create unlimited digital alternatives that improve and enrich organizational learning, upgrading an organization's ability to share and apply existing knowledge [35]. The second dimension of IT capability is concerned with integrated communications between the overall ITC of an organization and its main decision makers. The goal of these communications is business, planning and strategy analyses in the organization. The ongoing cooperation between business units and IT units establishes a real mutual trust between both of them, which facilitates information sharing and presentation of incredible services. In addition, it ensures the adaptability of organization workflows that require fundamental changes by information systems, procedures and operations of organization on a regular basis. Another dimension of IT capability is IT proactive stance, which describes how organizations are constantly in pursuit of innovative methods to realize and determine the optimal use of IT potentials on order to seize opportunities in the market. As a result, organizations will be well-equipped to define, choose and track IT developments [19] [35] [36].

IT capabilities control IT costs and provide the required business systems. Moreover, it affects organizational objectives through IT implementation. Some papers have examined IT capabilities from a resource- based view (RBV) [2] [22] [38] [39]. According to RBV, IT is a resource that creates competitive advantages, which leads to a superior performance [40]. According to Chen and Tsou (2012), based on RBV, IT Capability can be classified into four categories. IT infrastructure is the main foundation for delivering business applications and services, sharing information supplied by IT infrastructure in organizations. IT business experience enables an organization to merge IT strategy and business strategy. IT relationship resources represent an organization's ability to incorporate IT functions into business units and exploit IT resources. IT human resources are a major component of the IT asset base, serving as a strategic organizational resource and a major organizational capability.

As noted, various dimensions of ITC have been deliberated so far. Despite different terms used to describe these dimensions according to their features or type of ability, they overlap in many respects and should be categorized into a single group. In addition, most papers have focused on IT infrastructure capability as major ITC dimension.

\section{3- Research Methodology}

This study employs an exploratory mixed-methods approach to identify ITC dimensions and its evaluation indicators. To do so, the following steps were taken:

\section{3-1- Qualitative Section}

In the first step, previous research related to IT Capability was studied. for this purpose, an SLR approach was selected. Generally, the SLR process is performed in three 
consecutive stages: planning, execution and analysis of results [41].

\section{3-1-1- Review Design}

The review design defines the foundation of this review by describing SLR questions and search keywords.

This research was designed to identify the dimensions of ITC and its indicators. The SLR research question is as follows:

RQ. What are the dimensions of ITC and its indicators in the organization?

\section{3-1-1-1- Search Process}

We searched major scientific databases rather than specific books or reports on the assumption that the major research results described in books and reports are also usually cited or explained in scientific papers. The selected sources are:

- IEEE Xplore;

- Jstor;

- Science Direct - Elsevier;

- Springer Link;

- Google Scholar;

The keywords searched in the title, keywords, and abstract of the papers included: "Information technology capability" or "Information technology capability dimensions" or "Information technology capability measures" or "Information technology capability evaluation" or "IT capability"

\section{3-1-2- Review Conduction}

The review protocols of the SLR, which describe the structure and rules of review, are defined in this section.

\section{3-1-2-1- Inclusion and Exclusion Criteria}

All relevant studies were identified according to the predefined criteria. We included full papers in English published in peer-reviewed journals, conferences and workshops. In the case of duplicated studies, only the most thorough versions were selected. Inclusion and exclusion criteria are as follows:

Inclusion criteria:

- English peer-reviewed studies that address research questions

- Studies that explore ITC dimensions.

- Studies that explore ITC measurement and evaluation

- Studies that explore ITC

Exclusion criteria:

- Studies published in languages other than English
- Studies not pertained to the research questions

- Duplicated studies

\section{3-1-2-2- Study Selection}

The studies were checked for their relevance in the following process:

- Identifying relevant studies by searching defined keywords in the databases.

- Excluding studies based on the exclusion criteria.

- Analyzing titles and abstracts of paper and excluding irrelevant studies.

- Reading and assessing full-text papers.

- Reassessing the results of random studies.

- Extracting primary studies.

\section{3-1-2-3- Quality Assessment}

To control the strength of inferences and clarify outcomes derived from the studies, the following criteria were used for the evaluation of the selected studies:

- the thorough data analysis supported by evidence or theoretical arguments

- a study context similar to this research

- the support of study goals by the research design

\section{3-1-2-4- Synthesis}

The results obtained from searching keywords in databases are shown in Table 1. Table 2 shows the numbers of selected paper based on their type and Table 3 lists the citations of selected papers, which were obtained from Google Scholar.

Table 1: Results of study search

\begin{tabular}{|l|l|l|l|}
\hline Source & Found & Candidate & Selected \\
\hline Google Scholar & 48 & 43 & 18 \\
\hline Jstor & 22 & 9 & 7 \\
\hline IEEE Xplore & 95 & 3 & 1 \\
\hline Science Direct - Elsevier & 31 & 11 & 3 \\
\hline Springer Link & 59 & 2 & 0 \\
\hline Total & 230 & 66 & 29 \\
\hline
\end{tabular}

Table 2: Type of selected study and their numbers

\begin{tabular}{|l|l|l|}
\hline Study & No. & Percentage \\
\hline Journal papers & 27 & 93 \\
\hline Conference proceeding & 1 & $3 / 3$ \\
\hline Books & 1 & $3 / 3$ \\
\hline
\end{tabular}

Table 3: Citation for selecting papers

\begin{tabular}{|l|l|l|l|l|l|l|l|l|}
\hline$\#$ & Cited & Ref & $\#$ & Cited & Ref & $\#$ & Cited & Ref \\
\hline S1 & 1 & {$[42]$} & S11 & 136 & {$[30]$} & S21 & 38 & {$[36]$} \\
\hline S2 & 2 & {$[35]$} & S12 & 951 & {$[48]$} & S22 & 2807 & {$[21]$} \\
\hline S3 & 1122 & {$[27]$} & S13 & 489 & {$[49]$} & S23 & 1540 & {$[27]$} \\
\hline
\end{tabular}




\begin{tabular}{|l|l|l|l|l|l|l|l|l|}
\hline$\#$ & Cited & Ref & $\#$ & Cited & Ref & $\#$ & Cited & Ref \\
\hline S4 & 4977 & {$[37]$} & S14 & 273 & {$[50]$} & S24 & 670 & {$[55]$} \\
\hline S5 & 31 & {$[43]$} & S15 & 3 & {$[51]$} & S25 & 770 & {$[56]$} \\
\hline S6 & 20 & {$[44]$} & S16 & 177 & {$[23]$} & S26 & 33 & {$[28]$} \\
\hline S7 & 780 & {$[45]$} & S17 & 17 & {$[52]$} & S27 & 29 & {$[57]$} \\
\hline S8 & 919 & {$[46]$} & S18 & 306 & {$[53]$} & S28 & 131 & {$[10]$} \\
\hline S9 & 122 & {$[47]$} & S19 & 1144 & {$[54]$} & S29 & 5 & {$[29]$} \\
\hline $\begin{array}{l}\text { S1 } \\
0\end{array}$ & 223 & {$[32]$} & S20 & 593 & {$[19]$} & & & \\
\hline
\end{tabular}

\section{3-1-3- Results}

In this section, RQs are answered.

$R Q$. What are ITC dimensions and indicators in the organization?

The question is answered based on the analysis of extracted data. As a result, ITC indicators were identified and aggregated for further classification. After reexamination and elimination of overlapping indicators and the grouping of indicators, three main dimensions of ITC were identified by IT experts including IT infrastructure, IT management, and human resource capabilities.

\section{3-2- Quantitative Section}

In this section, the identified ITC dimensions and indicators are validated by a statistical analysis to present a more detailed model for ITC evaluation.

\section{3-2-1- Data Collection}

Information was gathered using a questionnaire with a 5point Likert scale (from strongly disagree (1) to strongly agree (5)). The factual and content validity of questionnaire were examined by IT experts and IT professors before distributing questionnaires among respondents.

Considering the definition and concept of an enterprise architecture, which plays an essential role in the information technology management [58], the statistical population of this research consisted of IT managers of organizations that were members of the Enterprise Architecture and Information Technology Association of Iran and IT constituted an integral part of their business. Accordingly, nearly 300 organizations were selected. We requested the IT Manager of these organizations to fill out questionnaire. Based on Morgan's table, a sample size of $\mathrm{n}=169$ organizations was selected, but we distributed 189 questionnaires to account for dropout and incomplete questionnaires. Finally, 168 questionnaires were returned. We also collected information about respondent's demographic variables, such as education, gender, and IT knowledge. According to the results, $13.7 \%$ of respondents were female and $86.3 \%$ were male. Regarding the level of education. $13.7 \%$ had a doctorate degree, $63.7 \%$ had a master's degree, $22 \%$ had a bachelor's degree and $0.6 \%$ had an associate degree. With respect to IT knowledge, $11.9 \%$ of respondents had very high, $40.5 \%$ had high, $43.5 \%$ had medium and $4.2 \%$ had low knowledge of IT. Prior to the factor analysis of ITC indicators, the reliability of questionnaire was evaluate using Cronbach's alpha coefficient (0.963), which was acceptable.

\section{3-2-2- Exploratory Factor Analysis (EFA)}

Exploratory factor analysis (EFA) can be used when the researcher has no theory about the research structure, or does not intend to incorporate the expected structure as a part of calculations. For the confirmatory factor analysis (CFA), researcher needs a theory of factor structure for the analysis in order to limit estimated parameters. There must be a certain degree of correlation between questionnaire's item and excessive correlation prevents the extraction of independent factors [59]. On the other hand, if such as correlation is below a certain degree, the unity matrix will be found. The significance of the Bartlett's test shows the correlation is adequate for factor analysis. The KaiserMeyer-Olkin (KMO) test surveys whether the items could be categorized into a smaller set of factors. A KMO value closer to one suggests the usefulness of the factor analysis for the data. However, the EFA cannot be performed properly if its values are below 0.5 [60].

In our study, KMO index value was 0.95 , which manifests the suitability of sampling and data numbers for factor analysis. Also, the significance of Bartlett's test of sphericity was less than $0.05(\mathrm{p}=0.00)$, indicating that the correlation matrix is suitable for data factor analysis.

After performing EFA for ITC indicators, four main dimensions were identified with eigenvalues greater than 1 , which is consistent with the gravel graph obtained from the software (Figure 1). Besides, these four dimensions explained $62.912 \%$ of variance in the ITC factors, which is acceptable.

For each of these four dimensions, a quadrant is extracted with a special value above 1 . Cronbach's alpha of all four dimensions is greater than 0.7 , exhibiting that the internal consistency is acceptable. The results show that all bivariate relationships between variables were statistically significant (Table 4).

Items $9,10,11$ and 12 loaded on IT resources capability and had a factor loading of over 0.4. However, according to expert's opinions they were excluded due to the lack of conceptual meanings. 
Table 4: Results of the ITC questionnaire EFA

\begin{tabular}{|c|c|c|c|c|c|}
\hline Factors (Dimensions) & Cronbach alpha coefficient & Factor loading & Items & Eigenvalue & Percentage of variance \\
\hline \multirow{9}{*}{$\begin{array}{l}\text { IT management } \\
\text { capability }\end{array}$} & \multirow[t]{9}{*}{0.911} & 0.458 & 5 & \multirow[t]{9}{*}{14.522} & \multirow[t]{9}{*}{18.592} \\
\hline & & 0.622 & 6 & & \\
\hline & & 0.559 & 19 & & \\
\hline & & 0.554 & 20 & & \\
\hline & & 0.658 & 21 & & \\
\hline & & 0.691 & 22 & & \\
\hline & & 0.732 & 23 & & \\
\hline & & 0.494 & 24 & & \\
\hline & & 0.506 & 25 & & \\
\hline \multirow{4}{*}{$\begin{array}{l}\text { IT } \begin{array}{r}\text { human } \\
\text { capability }\end{array} \\
\text { resources }\end{array}$} & \multirow[t]{4}{*}{0.828} & 0.548 & 26 & \multirow[t]{4}{*}{1.454} & \multirow[t]{4}{*}{17.308} \\
\hline & & 0.558 & 27 & & \\
\hline & & 0.677 & 28 & & \\
\hline & & 0.503 & 29 & & \\
\hline \multirow{8}{*}{$\begin{array}{l}\text { Implementation of IT } \\
\text { solutions capability }\end{array}$} & \multirow[t]{8}{*}{0.911} & 0.518 & 7 & \multirow[t]{8}{*}{1.205} & \multirow[t]{8}{*}{16.502} \\
\hline & & 0.573 & 8 & & \\
\hline & & 0.602 & 13 & & \\
\hline & & 0.77 & 14 & & \\
\hline & & 0.605 & 15 & & \\
\hline & & 0.674 & 16 & & \\
\hline & & 0.63 & 17 & & \\
\hline & & 0.568 & 18 & & \\
\hline \multirow{4}{*}{$\begin{array}{l}\text { IT } \quad \text { infrastructure } \\
\text { capability }\end{array}$} & \multirow[t]{4}{*}{0.793} & 0.758 & 1 & \multirow[t]{4}{*}{1.063} & \multirow[t]{4}{*}{10.51} \\
\hline & & 0.71 & 2 & & \\
\hline & & 0.52 & 3 & & \\
\hline & & 0.407 & 4 & & \\
\hline
\end{tabular}

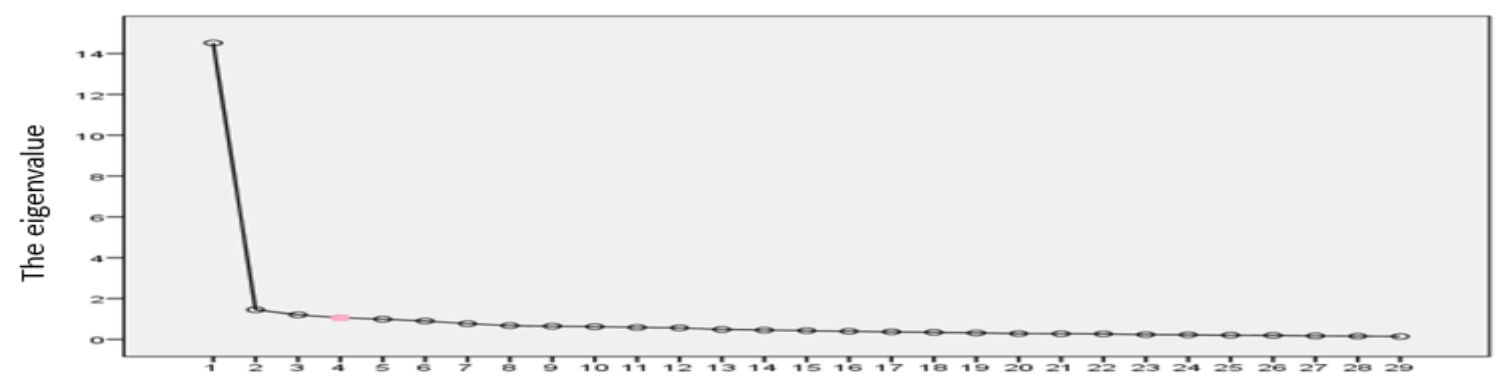

Number of Factors

Figure 1: Scree Plot of the ITC Questionnaire

\section{3-2-3- Research Hypotheses}

IT human resources capability: It describes skills required for resources management, including four types of skills: technology management, business function, interpersonal and management, and technical skills [61].

H1: IT capability has an effect on IT human resources capabilities.
IT management capability: " refers to IT staff's ability to manage resources in order to create business value for the organization" [53].

H2: IT capability has an effect on IT management capability.

Implementation of IT solutions capability: Previous research has not addressed key issues of this dimension of IT capability; however, according to this study, it refers to 
IT staff 's ability to manage IT project implementation and support all steps and activities that lead to IT solutions.

H3: IT capability has an effect on the implementation of IT solutions capability.

IT infrastructure capability: "An organization's capacity to organize a set of shareable platforms, which captures the extent to which an organization is dexterous at providing data management services and architectures, application portfolio, network communication services and services" [19].

H4: IT capability has an effect on the implementation of IT infrastructure capability.

\section{3-2-4- Confirmatory Factor Analysis (CFA)}

The confirmatory factor analysis (CFA) is usually conducted to minimize the difference between the estimated and observed matrices [62]. In the second-order confirmatory factor model, the factors obtained from the observed variables are influenced by other latent variables at a higher level. Accordingly, in addition to investigating the relationship between observable variables and factors, the association between latent variables and factors is also examined [63]. All four factors of the study (ITC dimensions) measure ITC (as a latent variable). In this section, the fitness of measurement and structural model is investigated by CFA using SmartPLS.

\section{3-2-4-1- Evaluation of Measurement Model}

This section evaluates reliability and validity of the model. Reliability is assessed in three ways: evaluation of factor loading, Cronbach's alpha and composite reliability. Factor loading values greater than 0.4 are suitable. Also, Cronbach's alpha coefficients greater than 0.70 indicate that the measurement model is reliable [64]. The value of composite reliability can vary between 0 and 1 with values higher than 0.6 being considered as acceptable [65]. As shown in Table 5, the model reliability is acceptable.

Table 5: Results of Validity and Reliability

\begin{tabular}{|c|c|c|c|c|c|c|}
\hline Variables & Item icon & Factor loading & T values & Cronbach alpha coefficient & The Composite reliability & AVE \\
\hline \multirow{4}{*}{$\begin{array}{l}\text { IT } \\
\text { infrastructure } \\
\quad \text { capability }\end{array}$} & ITC1 & 0.823 & 24.07 & \multirow[t]{4}{*}{0.79} & \multirow[t]{4}{*}{0.86} & \multirow[t]{4}{*}{0.621} \\
\hline & ITC2 & 0.784 & 17.25 & & & \\
\hline & ITC3 & 0.788 & 21.01 & & & \\
\hline & ITC4 & 0.755 & 16.22 & & & \\
\hline \multirow{8}{*}{$\begin{array}{l}\text { Implementation } \\
\text { of IT } \\
\text { solutions } \\
\text { capability }\end{array}$} & ITC13 & 0.837 & 33.9 & \multirow[t]{8}{*}{0.91} & \multirow[t]{8}{*}{0.93} & \multirow[t]{8}{*}{0.625} \\
\hline & ITC14 & 0.86 & 37.17 & & & \\
\hline & ITC15 & 0.824 & 29.57 & & & \\
\hline & ITC16 & 0.776 & 23.47 & & & \\
\hline & ITC17 & 0.758 & 19.47 & & & \\
\hline & ITC18 & 0.68 & 15.06 & & & \\
\hline & ITC7 & 0.799 & 31.5 & & & \\
\hline & ITC8 & 0.78 & 22.96 & & & \\
\hline \multirow{9}{*}{$\begin{array}{l}\text { IT human } \\
\text { resources } \\
\text { capability }\end{array}$} & ITC19 & 0.709 & 12.4 & \multirow[t]{9}{*}{0.91} & \multirow[t]{9}{*}{0.92} & \multirow[t]{9}{*}{0.586} \\
\hline & ITC20 & 0.721 & 16.8 & & & \\
\hline & ITC21 & 0.812 & 29.4 & & & \\
\hline & ITC22 & 0.762 & 20.7 & & & \\
\hline & ITC23 & 0.806 & 31.7 & & & \\
\hline & ITC24 & 0.778 & 22.8 & & & \\
\hline & ITC25 & 0.749 & 19.15 & & & \\
\hline & ITC5 & 0.791 & 17.1 & & & \\
\hline & ITC6 & 0.804 & 25.8 & & & \\
\hline \multirow{4}{*}{$\begin{array}{l}\text { IT management } \\
\text { capability }\end{array}$} & ITC26 & 0.813 & 27.02 & \multirow[t]{4}{*}{0.82} & \multirow[t]{4}{*}{0.88} & \multirow[t]{4}{*}{0.659} \\
\hline & ITC27 & 0.849 & 36.32 & & & \\
\hline & ITC28 & 0.829 & 27.07 & & & \\
\hline & ITC29 & 0.755 & 15.29 & & & \\
\hline IT capability & - & - & - & 0.95 & 0.96 & 0.782 \\
\hline
\end{tabular}

The convergent validity is assess based on the average variance extracted (AVE). According to [66], AVE $\geq 0.50$ manifests a sufficient degree of convergent validity, meaning that the latent variable (constructs) explains more than half of variance in its indicators. The discriminant validity test shows the degree of variance in indicators that could be explained by variance in the construct [67]. As the results of Table 5 show, the convergent validity and discriminant validity test of the research model were acceptable.

The normality of research data was evaluated using Kolmogorov-Smirnov test. The results showed that the distribution of research variable did not follow the normal statistical distribution. Moreover, Spearman's rank correlation coefficient was conducted to assess the correlation between ITC variable and other variables (4 
identified factors). The correlation significance between all variables were less than 0.05 , which is acceptable.

\section{3-2-4-2- Evaluation of Structural Model}

The effect of an exogenous variable on an endogenous variable is evaluated using $\mathrm{R}^{2}$ coefficient, which is related to the latent (dependent) variables of the model. The three values of $\mathrm{R}^{2}$ coefficient, i.e. $0.19,0.33$ and 0.67 , are the criterion for the weak, moderate and strong values [63]. The results of the structural model assessment are presented in Table 6 . Based on the results, the overall model had an acceptable fit.

Table 6: Tests of hypotheses and results of R2 criteria

\begin{tabular}{|l|l|l|l|l|}
\hline Variables & $\mathbf{R}^{2}$ & $\begin{array}{l}\text { Related } \\
\text { Hypotheses }\end{array}$ & $\begin{array}{l}\text { T- } \\
\text { value }\end{array}$ & $\begin{array}{l}\text { Path } \\
\text { Coefficient }\end{array}$ \\
\hline $\begin{array}{l}\text { IT human resources } \\
\text { capability }\end{array}$ & 0.71 & $\mathrm{H} 1$ & 37.616 & 0.846 \\
\hline $\begin{array}{l}\text { IT management } \\
\text { capability }\end{array}$ & 0.89 & $\mathrm{H} 2$ & 102.68 & 0.893 \\
\hline $\begin{array}{l}\text { Implementation of IT } \\
\text { solutions capability }\end{array}$ & 0.84 & $\mathrm{H} 3$ & 72.807 & 0.848 \\
\hline $\begin{array}{l}\text { IT infrastructure } \\
\text { capability }\end{array}$ & 0.67 & $\mathrm{H} 4$ & 29.875 & 0.821 \\
\hline
\end{tabular}

\section{3-2-5- Model Validation}

Tenenhaus et al. [68] have suggested a global criterion for the goodness of fit (i.e., GoF index), which accounts for the performance of the PLS model and validates both the measurement model and the structural model with a focus on overall prediction performance of the model. Accordingly, three values of $0.01,0.25$ and 0.36 were considered as weak, moderate and strong values for GOF. In this research, GOF was equivalent to 0.696 , which shows the strong fitness of the overall research model.

\section{4- Research Findings}

According to the findings of the qualitative and quantitative sections, the ITC dimensions and its indicators were finally identified. In this paper, we proposed a model of ITC dimensions that comprises 4 dimensions and 25 indicators, as shown in Table 7. As mentioned earlier, 3 ITC dimensions and 29 indicators were identified in the qualitative section, but after performing CFA in the quantitative section, the number of identified dimensions increased to four and the number of indicators dropped to 25.

The presented model includes both tangible and intangible IT capabilities. Tangible capabilities include technical and infrastructure elements (appropriate communication network, formats of information, standards, wellintegrated web applications), and intangible IT capabilities include the business group's knowledge and awareness of IT and their ability to interact with the business group.
According to the findings, the implementation of IT solutions capability dimension, despite its strong correlation with ITC, has received scant attention in the literature. However, IT infrastructure capabilities, despite its weak correlation with ITC, has received greatest attention in previous research (Table 6).

IT infrastructure capability includes 4 indicators IT management capability includes 9 indicators, Implementation of IT solutions capability includes 8 indicators and finally IT human resources capability includes 4 indicators.

\section{5- Discussion}

Many studies have identified different ITC dimensions and indicators. These studies contain limitations and deficiencies that can be mentioned:

In most of previous studies, IT capability is considered based on technology components, as a set of shared, tangible, and technological resources [16] [17] [48] [55] [69] [70]. However, IT capability covers a wide range of capabilities. For example, the knowledge and expertise of IT staff is one of major IT capabilities that play an important role in improving organizational performance and achieving competitive advantage [42] [50] [53] [61]. Identifying all ITC dimension in order to evaluate its status requires a comprehensive review that incorporates different perspectives. In addition, ITC is a dynamic rather than static organizational capability. In diverse organizations, the role and nature of ITC are different. However, in many organizations, ITC can support the business and provide a competitive advantage, which acts as a business driver [26] [34]. Therefore, identifying all types and dimensions of ITC requires examining a wide array of organizations where IT plays different roles.

In the literature, some papers have explicitly identified the ITC dimensions [27] [28] [29]. Chen and Tsou [30], while evaluating the impact of ITC on the organizational performance of Nigerian banks, identified different dimensions of ITC. Their results laid the foundation for many other studies. For the first time, Bhatt and Grover [27] presented a classification of ITC dimensions, which contained only 4 indicators introduced in this study. The two dimensions of IT management capabilities and IT solutions capabilities were not considered in their study. Thus, out of 19 indices related to these two dimensions, only one (business experience of IT group) was mentioned. Yoon [28] focused on IT management capabilities, covering 5 out of 9 indicators associated with this dimension. It is worth noting that Yoon [28] considers development, deployment and management of information systems including ERP, SCM, CRM, and KMS as an organization's IT capabilities. However, depending on the type and requirements of an organization, no information systems may be necessary. However, the present study 
considers the enterprise architecture development as one of IT management capabilities that help develop information systems in the organization. Zhang et al. [29] presented a classification of ITC dimensions that consisted of only 5 indicators presented in this study, leaving out. Implementation of IT solutions capabilities wasn't considered by them. Chen and Tsou [30] presented a relatively complete set of ITC dimensions. Although their model addressed 4 dimensions of IT capability, they only considered 8 indicators introduced in the present research. Table 7 compares ITC identified in some of previous studies with the present article. As can be seen, the types of ITC identified in the present study exceed that of other studies. Risk management, data and database management, asset management and infrastructure management as well as IT services management system (planning, development and support of IT services) have been overlooked in the aforementioned studies.

To date, several enterprise architecture frameworks have used capability notation, considering the development of organizational capability as an important component of business architecture, including TOGAF, DODAF, MODAF, Service-Oriented Architecture (SOA), NAF, and Archimate frameworks [71]. The purpose of identifying ITCs in an enterprise architecture is modeling and creating an IT capability guide that offers several benefits, including planning key ITCs improvement and aligning ITC with business strategies. Up to now, various business capability frameworks and roadmaps have been developed to facilitate the identification and evaluation of business capabilities maturity. The IT capability maturity framework (ITCMF) evaluates the ITC maturity in organizations [72]. It consists of four primary categories, where each category covers several sub-capabilities known as IT capabilities, which are basically distinct from ITC definition in the present study. In fact, each category represents a role that could be assumed by an IT unit in an organization. ITCMF builds a bridge between organizational change and IT capability [73], but it falls short of a clear evaluation of ITC in organizations that are weak in this respect.

\begin{tabular}{|c|c|c|c|c|c|c|}
\hline Dimensions & $\begin{array}{l}\text { ITC Type } \\
\end{array}$ & This research & {$[30]$} & [29] & {$[28]$} & [27] \\
\hline \multirow[t]{4}{*}{ IT infrastructure capabilities } & Providing appropriate network communication services & $*$ & $*$ & $*$ & $*$ & $*$ \\
\hline & Adapting and sharing various formats of information and data & $*$ & & & & \\
\hline & Complying with security standards and risk management & $*$ & & & & \\
\hline & Using well-integrated web applications & $*$ & $*$ & & & \\
\hline \multirow[t]{8}{*}{ IT management capabilities } & Developing and implementing an strategic plan of ICT & * & & * & * & \\
\hline & Applying enterprise architecture & $*$ & & & & \\
\hline & Ensuring interaction between IT units and other business units & $*$ & * & & $*$ & $*$ \\
\hline & $\begin{array}{l}\text { Understanding how IT supports competitive advantages as well as IT } \\
\text { investment value. }\end{array}$ & $*$ & & $*$ & $*$ & \\
\hline & Evaluating IT performance & $*$ & & & $*$ & \\
\hline & Planning for control security and complying with security standards & $*$ & & & $*$ & \\
\hline & Scheduling for risk management and disaster recovery & $*$ & & & & \\
\hline & Planning for IT resources and asset management & $*$ & $*$ & & & \\
\hline
\end{tabular}

IT governance is another concept closely related to IT capability. IT governance represents the process of controlling and monitoring decisions related to an organization's IT capability [74]. A variety of frameworks, including COBIT, ITIL, Val IT have been developed for IT governance. In general, IT governance frameworks constitute a set of best practices and procedures that help organizations build their value through ITC and achieve their strategic goals. An important part of IT governance is evaluation and control. COBIT is a framework for monitoring and managing IT activities through which IT resources are managed in a way to obtain IT objectives [31]. COBIT also includes a maturity model that illustrates the status of IT management processes in organizations at six levels. The state of IT capabilities should also be noted. ITIL is an IT governance framework at the IT service level. Thus, it evaluates IT capability only at the level of IT service development and support. The evaluation of ITC through the ITC map presented in this research does not only lead to IT management and IT services evaluation. It assesses the status of an organization's IT capabilities at the levels of ITC management, IT services and solutions, IT infrastructure and staff expertise, and clarifies ITC weaknesses, which contribute to the management, control and also improvement of an organization's ITC. In light of the above, the main innovation and contribution of this research are as follows:

- ITC dimensions were identified in a systematic literature review (qualitative review); the quantitative statistical methods relied on resource-based and strategic-based approaches.

- The proposed ITC map identified more ITC indicators than previous research did. New ITC indicators have not been considered in previous classifications.

- The proposed ITC map detects ITC in accordance with four layers of enterprise architecture (business, application, data and infrastructure). It can be used as an enterprise architecture framework in the IT governance management that evaluates an organization's ITC status. . 


\begin{tabular}{|c|c|c|c|c|c|c|}
\hline Dimensions & ITC Type & This research & [30] & [29] & [28] & [27] \\
\hline & Supporting modern IT usage methods and innovations & $*$ & $*$ & & & \\
\hline \multirow{8}{*}{$\begin{array}{l}\text { Implementation of IT } \\
\text { solutions capabilities }\end{array}$} & Managing ICT projects & * & * & * & * & \\
\hline & Managing IT providers (software vendors, networks, data centers) & $*$ & & & & \\
\hline & Testing and implementing IT services & * & & & & \\
\hline & Supporting IT services & $*$ & & & & \\
\hline & Backing up & * & & & & \\
\hline & Delivering and exploiting IT solutions & $*$ & & & & \\
\hline & Maintaining and backing up an organization's databases & $*$ & & & & \\
\hline & Setting up service level agreements (SLAs) & $*$ & & & & \\
\hline \multirow{4}{*}{$\begin{array}{l}\text { IT human resource } \\
\text { capabilities }\end{array}$} & Encouraging IT employees to learn & * & & & & \\
\hline & $\begin{array}{l}\text { Encouraging IT employees and inter-unit effort, dealing with } \\
\text { business problems and promoting teamwork }\end{array}$ & $*$ & & & & $*$ \\
\hline & Raising IT employee's awareness of business & $*$ & $*$ & * & & $*$ \\
\hline & Recruiting expert and skilled IT employees & $*$ & $*$ & $*$ & $*$ & \\
\hline
\end{tabular}

\section{6- Limitations and Future Work}

This paper offers some avenues of research that could be built upon in future research. This paper focused on different dimensions of ITC and its indicators in order to evaluate and improve such dimensions in organizations. The indicators presented for each IT capability in the research model could be merged in IT frameworks such as IT4IT and COBIT, to be further developed. The future research can analyze the weight and significance of each dimension and indicator. Furthermore, a maturity model of ITC dimension could be developed by ranking ITC indicators or identifying and defining a range of levels for them in the organization. This research can also benefit from a wider range of data from various industries. Also, the capability of IT in a particular industry can also be measured in future works based on this model.

\section{7- Conclusion}

Organizations are increasingly in search of ways to derive more business value from their IT investments. Developing an organization's IT capability is a common approach to achieve this goal. However, the absence of a comprehensive, structured and validated model for evaluating ITC and its dimension status is felt. The goal of this study was to explicate the nature of IT capability dimensions and identify the dimensions of ITC and their indicators. Through a meticulous review of ITC literature and related academic theory as well as statistical analysis, a model for evaluating ITC dimension was proposed, which could be used as a map, checklist or questionnaire that contains ITC dimensions and their indicators. According to this model, an organization's IT capability comes from underlying strengths in four main types of ITC including IT management, IT human resources, IT infrastructure, and implementation of IT solutions, which are evaluated by 25 indicators. Together, they serve as a guide for studying ITC status in an organization.

\section{References}

[1] N. A. A. Hamid, C. W. Liew, N. H. Abdullah, and S. S. Omar, "The role of information technology human capability in the implementation of information technology governance (ITG): a systematic literature review on malaysian organizations," Technology and Engineering Systems Journal, Vol. 4, No. 4, 314-322, 2019.

[2] A. S. Bharadwaj, "A resource-based perspective on information technology capability and firm performance: An empirical investigation," MIS quarterly, Vol. 24, No. 1, pp.169196, 2000.

[3] S. Mithas, N. Ramasubbu, M. S. Krishnan and V. Sambamurthy, "Information technology infrastructure capability and firm performance: An empirical analysis. Working paper," Ross School of Business, University of Michigan, Ann Arbor, 2005.

[4] G. K. Chepkole, and J. Deya, "Effect of strategic capability on competitive advantage of information technology firms in Nairobi City County, Kenya," International Academic Journal of Human Resource and Business Administration, Vol. 3, No. 5, 104-127, 2019.

[5] C. H. Chen, and T. Cates, T. "The role of information technology capability and innovative capability: An empirical analysis of knowledge management in healthcare," International Management Review, Vol. 14 No. 1, 5-16, 2018.

[6] J. Luftman, K. Lyytinen, and T. B. Zvi, "Enhancing the measurement of information technology (IT) business alignment and its influence on company performance," Journal of Information Technology, Vol. 32, No. 1, 26-46, 2018.

[8] P. Mikalef, and A. Pateli, "Information technology-enabled dynamic capabilities and their indirect effect on competitive performance: Findings from PLS-SEM and fsQCA," Journal of Business Research, Vol. 70, No.1, 1-16, 2017.

[9] M. Queiroz, P. Tallon, R. Sharma, and T. Coltman, "The role of IT application orchestration capability in improving agility and performance, The Journal of Strategic Information Systems," Vol. 27, No. 1, 4-21, 2018.

[10] M. Zhang, S. Sarker and S. Sarker, "Unpacking the effect of IT capability on the performance of export-focused SMEs: A report from China," Information Systems Journal, Vol. 18, No. 4, pp.357-380, 2008.

[11] H. Liu, K. Ke, K. Wei and ZH. Hua, "The impact of IT capabilities on firm performance: The mediating roles of 
absorptive capacity and supply chain agility," Decision Support Systems, Vol. 54, pp.1452-1462, 2013.

[12] K. J. Ringim, M. R. Razalli and N. Hasnan, N "The relationship between information technology capability and organizational performance in Nigerian banks," International Journal of Business Research and Development, Vol. 4, No. 2, pp.1- 10, 2015.

[13] H. C. Chae, C. E. Koh and K. O. Park, "Information technology capability and firm performance: Role of industry," Information and Management, Vol. 55, No. 5, pp.525-546, 2018.

[14] Z. Wang, D. Q. Yao, X. Yue and J. J. Liu, "Impact of IT Capability on the Performance of Port Operation," Production and Operations Management, Vol. 27, No. 11, pp.1996-2009, 2017.

[15] U. Hameed, M. Shabbir, A. Raza and A. Salman, "Remedies of low performance among Pakistani e-logistic companies: The role of firm's IT capability and information communication technology (ICT)," Uncertain Supply Chain Management, Vol. 7, No. 2, 2018.

[16] J. Braojos, J. Benitez and J. Llorenz, "How do social commerce-IT capabilities influence firm performance? Theory and empirical evidence," Information \& Management, Vol. 56, No. 2, pp.155-171, 2019.

[17] J. B. Barney, "Firm resources and sustained competitive advantage," Journal of Management, Vol. 17, No. 1, pp.99-120, 1991.

[18] M. Wade and J. Hulland, "Review: the resource-based view and information systems research: review, extension, and suggestions for future research," MIS Quarterly, Vol. 28, No. 107, 2004.

[19] Y. Lu and K. Ramamurthy, "Understanding the link between information technology capability and organizational agility: an empirical examination," MIS Quarterly, Vol. 35, No. 4, pp.931-954, 2011.

[20] V. Sambamurthy and R. W. Zmud, "At the heart of success: organization-wide management competencies," in Steps to the Future: Fresh Thinking on the management of IT-Based Organizational transformation, Sauer, C. and P. Yetton, P. (Eds.), San Francisco, CA: Jossey-Bass Publishers, 1997, pp.143-164.

[21] F. J. Mata, W. L. Fuerst and J. B. Barney, "Information technology and sustained competitive advantage: a resourcebased analysis," MIS Quarterly, Vol. 19, No. 4, pp.487-505, 1995.

[22] B. B. Tyler, "The complementarity of cooperative and technological competencies: a resource-based perspective," Journal of Engineering and Technology Management, Vol. 18, No. 1, pp.1-27, 2001.

[23] S. H. Huang, C. Ou, C. M. Chen and B. Lin, "An empirical study of relationship between IT investment and firm performance: a resource-based perspective," European Journal of Operational Research, Vol. 173, No. 3, pp.984-999, 2006.

[24] J. Benitez-Amado and R. M. Walczuch, "Information technology, the organizational capability of proactive corporate environmental strategy and firm performance: A resource-based analysis," European Journal of Information Systems, Vol. 21, pp.664-679, 2012.

[25] L. Kang, C. H. Tan and J. L. Zhao, “Organizational quest for competitive advantage through innovation: where should IT capability be focused?," in Twenty-Second Pacific Asia Conference on Information Systems, Yokohama, Japan, 2018.

[26] J. G. Kamau, T. A. Senaji and S. C. Nzioki, "Effect of information technology capability on competitive advantage of the Kenyan banking sector," International Journal of Technology and Systems, Vol. 4, No. 1, pp.1-20, 2019.

[27] D. G. Bhatt and V. Grover, "Types of information technology capabilities and their role in competitive advantage: an empirical study," Journal of Management Information Systems, Vol. 22, No. 2, pp.253-277, 2005.

[28] C.Y. Yoon, "Measuring enterprise IT capability: a total IT capability perspective," Knowledge-Based Systems, Vol. 29, No. 7, pp.1-6, 2011.

[29] M. Zhang, M. Brodke and J. McCullough, "Cross-cultural reliability and validity of a scale to measure information technology capability," Journal of Technology Research, Vol. 2, No. 1, pp.1-20, 2010.

[30] J. S. Chen and H. T. Tsou, "Performance effects of IT capability service process innovation and the mediating role of customer service," Journal of Engineering and Technology Management, Vol. 29, No. 1, pp.71-94, 2012.

[31] J. W. Lainhart, "COBIT: a methodology for managing and controlling information technology risks and vulnerabilities. Journal of Information Systems, Vol. 1, No. 14, pp. 21-25, 2000.

[32] Y. Chen, Y. Wang, S. Nevo, J. Jin, L. Wang, and W. S. Chow, "IT capability and organizational performance: the roles of business process agility and environmental factors," European Journal of Information Systems, Vol. 23, No. 3, pp.326-342, 2014.

[33] J. W. Ross, C. M. Beath, and D. L. Goodhue, "Develop long-term competitiveness through IT assets," Sloan Management Review, 38, No. 1, pp.31-45, 1996.

[34] Z. Aiqun, "An IT Capability Approach to Informatization Construction of Higer Education Institutions," Procedia Computer Science, Vol.131, pp.683-690, 2018.

[35] A. Q. Bataineh, M. G. Al-Abdallah and A. Y. Alhadid, "The role of information technology capabilities in capitalizing market agility in jordanian telecommunications sector," International Journal of Academic Research in Business and Social Sciences, Vol. 5, No. 8, pp.90-101, 2015.

[36] H. Mao, S. Liu and J. Zhang, "How the effects of IT and knowledge capability on organizational agility are contingent on environmental uncertainty and information intensity," Information Development, Vol. 31, No. 4, pp.358-382, 2014.

[37] A. S. Bharadwaj, S. G. Bharadwaj and B. R. Konsynski, "Information technology effects on firm performance as measured by Tobin's q," Management Science, Vol. 45, No. 7, pp.1008-1024, 1999.

[38] H. S. Han, J. N. Lee and Y. W. Seo, "Analyzing the impact of a firm's capability on outsourcing success: a process perspective," Information and Management, Vol. 45, No. 1, pp.31-42, 2008.

[39] F. Lai, D. Li, Q. Wang and X. Zhao, "The information technology capability of third-party logistics providers: a resource-based view and empirical evidence from China," Journal of Supply Chain Management, Vol. 44, No. 3, pp.22-38, 2008.

[40] M. Zhang, "Information systems strategic flexibility and firm performance: an empirical investigation," Journal of 
Engineering and Technology Management, Vol. 22, No. 3, pp.163-184, 2005.

[41] B. Kitchenham and S. Charters, Guidelines for performing systematic literature reviews in software engineering (Report No. EBSE-2007-01"School of Computer Science and Mathematics, Keele University, 2007.

[42] I. Bakan and ZH. Sekkeli, "Types of information technology capability and their impacts on competitiveness," Research Journal of Business and Management, Vol. 4 No. 2, pp.212-220, 2017.

[43] R. Bi, R. M. Davison, B. Kam and K. X. Smyrnios, "Developing Organizational Agility through IT and Supply Chain Capability," Journal of Global Information Management, Vol. 21, No. 4, pp.38-55, 2013.

[44] B. Boar, "Cost Effective Strategies for Client/ Server Systems. New York, NY: Wiley and Sons, 1996.

[45] M. Broadbent, P. Weill and D. S. Clair, "The implications of information technology infrastructure for business process redesign," MIS quarterly, Vol. 23, No. 2, pp.159-182, 1999.

[46] T. A. Byrd and D. E. Turner, "Measuring the flexibility of information technology infrastructure: exploratory analysis of a construct," Journal of Management Information Systems, Vol.1, No.17, pp.167-208, 2000.

[47] Y. Chen, Y. Wang, S. Nevo, J. Benitez-Amado and G. Kou, "IT capabilities and product innovation performance: The roles of corporate entrepreneurship and competitive intensity," Information \& Management, Vol. 52, No. 6, pp. 643-657, 2015.

[48] N. B. Duncan, "Capturing flexibility of information technology infrastructure: A study of resource characteristics and their measure," Journal of Management Information Systems, Vol. 12, No. 2, pp.37-57, 1995.

[49] R. G. Fichman, "Real options and IT platform adoption: Implications for theory and practice," Information Systems Research, Vol. 15, No. 2, pp.132-154, 2004.

[50] L. Fink and S Neumann, "Gaining agility through IT personnel capabilities: the mediating role of IT infrastructure capabilities," Journal of the Association for Information Systems, Vol. 8, No. 8, pp.440-462, 2007.

[51] N. H. Hassan, N. I. Arshad, E. E. Mustapha and J. Jaafar, “ $A$ literature review: exploring organizational learning orientation as antecedent of information technology (IT) infrastructure capability to achieve organizational agility. In Third International Conference on Research and Innovation in Information Systems (ICRIIS), Kuala Lumpur, Malaysia, 2013.

[52] M. A. Karimi, A. Amini and M. Latifi, "The impact of information technology capability on firm performance; a focus on employee customer profit chain," Iranian Journal of Management Studies (IJMS), Vol. 7, No. 1, pp.95-120, 2014.

[53] G. Kim, B. Shin., K. K. Kim and H. G. Lee, "IT capabilities, process-oriented dynamic capabilities, and firm financial performance," Information Systems, Vol. 12, No. 7, pp.491-492, 2011.

[54] D. M. Lee, E. M. Trauth and D. Farwell, "Critical skills and knowledge requirement of IS professionals: a joint academic and industry investigation," MIS Quarterly, Vol. 19, No. 3, pp.313340, 1995.

[55] P. Tallon, "Competing perspectives on the link between strategic information technology alignment and organizational agility: insights from a mediation model," MIS Quarterly, Vol. 35, No. 2, pp.463-486, 2011.

[56] P. Weill, M. Subramani and M. Broadbent, "Building IT infrastructure for strategic agility," MIT Sloan Management Review, Vol. 44, No. 1, pp.57-66, 2002.

[57] M. Zhang, "Information Technology Capability, Organizational Culture, and Export Performance. Washington State University, Washington, 2005.

[58] J. W. Ross, P. Weill and D. C. Robertson, "Enterprise architecture as strategy: creating a foundation for business execution. Boston, MA: Harvard Business School Press, 2006.

[59] B. Thompson, "Exploratory and confirmatory factor analysis: Concepts and applications. Washington, DC: American Psychological Association, 2004.

[60] B. Williams, T. Brown and O. Andrys, "Exploratory factor analysis: a five-step guide for novices," Australasian Journal of Paramedicine, Vol. 8, No. 3, pp.1-13, 2010.

[61] J. Y. Park, K. S. Im and J. S. Kim, "The role of IT human capability in the knowledge transfer process in IT outsourcing context," Information and Management, Vol. 48, No. 1, pp.5361, 2011.

[62] J. B. Schreiber, A. Nora, F. K. Stage, EA. Barlow and J. King, "Reporting structural equation modeling and confirmatory factor analysis results: a review," the Journal of Educational Research, Vol. 99, No. 6, pp.323-337, 2006.

[63] W. W. Chin, B. L. Marcolin and P. R. Newsted, "A partial least squares latent variable modeling approach for measuring interaction effects: Results from a monte carlo simulation study and voice mail emotion/adoption study," in Proceedings of the Seventeenth International Conference on Information System, Cleveland, Ohio. 1996, pp.21-41.

[64] J. C. Nunnally, "Psychometric theory. 2nd (ed.) New York: McGraw-Hill Book Company, 1978.

[65] R. P. Bagozzi and Y. Yi, "On the evaluation of structural equation models," Journal of the Academy of Marketing Science, Vol. 16, No. 1, pp.74-94, 1988.

[66] C. Fornell and D. F. Larcker, "Evaluating structural equation models with unobservable variables and measurement errors," Journal of Marketing Research, Vol. 18, No. 1, pp.3950. 1981,

[67] W. M. A. B. W. Afthanorhan, "A comparison of partial least square structural equation modeling (PLS-SEM) and covariance based structural equation modeling (CB-SEM) for confirmatory factor analysis," International Journal Engineering and Science Innovative Technologies (IJESIT), Vol. 2, No. 5, pp.8, 2013.

[68] M. Tenenhaus, S. Amato and V. Esposito Vinzi, "A global goodness-of-fit index for PLS structural equation modelling," Proceedings of the XLII SIS Scientific Meeting, pp. 739742"Padova: CLEUP, 2004.

[69] M. J. Earl, "Management Strategies for Information Technology. Upper Saddle River, NJ: Prentice Hall, 1989.

[70] Q. Xianfeng, L. Boxiong and G. Zhenwei, G. "Conceptual model of IT infrastructure capability and its empirical justification," TSINGHUA SCIENCE AND TECHNOLOGY, Vol. 13, No. 3, 2008.

[71] J. Zdravkovic, J. Stirna and J. Grabis, "Capability consideration in business and enterprise architecture frameworks," in Capability Management in Digital Enterprises, 
K. Sandkuhl and J. Stirna, (Eds.), Springer International Publishing, Cham, 2018, pp.41-56.

[72] M. Carcary, "IT Risk Management: A Capability Maturity Model Perspective," Electronic journal of information systems evaluation, Vol. 16, No. 1, 2013.

[73] S. McLaughlin, "Using the IT-CMF as an Enabler for Transformational Change," IVI White Paper Series, 2013.

[74] P. Zhang, K. Zhao and R. L. Kumar, "Impact of IT Governance and IT Capability on Firm Performance," Infromation Systems Management, Vol. 33, pp.17, 2016.

Mina Ranjbarfard received the B.S. degree in industry engineering from Bu-ali sina University, Hamedan, Iran, in 2005. She received the M.Sc. and Ph.D. degree in industry engineering from Tarbiat Modares University, Tehran, Iran, in 2008 and 2013, respectively. Now, she is an assistant professor in the faculty of social sciences and economics at Alzahra University, Tehran, Iran. Her research interests include knowledge management, business process management, information system management, enterprise architecture, data mining, business intelligence and business analytics.

Seyedeh Reyhaneh Mirsalari received the B.S. degree in information technology engineering from Payame Noor University, Shahriar Branch, Iran, in 2012 and She received the M.Sc. degree in information technology management from Alzahra University, Tehran, Iran, in 2016. Her research interests include knowledge management, business process management, enterprise architecture, data mining, business intelligence, business analytics and information system management. 